\title{
Pressurized Hot Water Extraction of Alkaloids in Goldenseal
}

\author{
Janes Mokgadi ${ }^{1}$, Charlotta Turner $^{2}$, Nelson Torto ${ }^{1}$ \\ ${ }^{1}$ Department of Chemistry, Rhodes University, Grahamstown, South Africa \\ ${ }^{2}$ Department of Chemistry, Lund University, Centre for Analysis and Synthesis, Lund, Sweden \\ Email:jmokgadi@yahoo.com
}

Received January 25, 2013; revised February 25, 2013; accepted March 19, 2013

Copyright (C) 2013 Janes Mokgadi et al. This is an open access article distributed under the Creative Commons Attribution License, which permits unrestricted use, distribution, and reproduction in any medium, provided the original work is properly cited.

\begin{abstract}
A quick, efficient and environmentally beneficial approach for the extraction of alkaloids in goldenseal based on pressurized hot water extraction (PHWE) is presented. PHWE was evaluated following the extraction of hydrastine and berberine which are the two main alkaloids of goldenseal. The effects of temperature and other parameters on extraction yields were monitored by high performance liquid chromatography coupled to diode array detector (HPLC-DAD). The extraction yields were compared to those achieved through reflux and ultrasonic extraction methods. PHWE employed hot water at an optimal temperature of $140^{\circ} \mathrm{C}$, a pressure of 50 bars and flow rate of $1 \mathrm{~mL} \cdot \mathrm{min}^{-1}$ for extraction experiments conducted in the dynamic mode. Both PHWE and conventional methods achieved comparable extraction yields. Reflux and ultrasonic extractions had procedures that were slower (over $6 \mathrm{~h}$ ) and employed large quantities $(200 \mathrm{~mL}) \mathrm{of}$ organic solvents. The PHWE method was simple and relatively fast as extraction was achieved in $15 \mathrm{~min}$. At $95 \%$ confidence level $(n=3)$, reflux and ultrasonic methods recorded extraction yields that were not significantly different from that of PHWE. Moreover, PHWE employed a more readily available "green" solvent, (water) to achieve comparable results to those of conventional methods which utilized organic solvents. The percentage relative standard deviations (\%RSD) for the extraction yields were less than $3 \%$ in all cases indicating the high reproducibility of the method. However, when using PHWE to extract thermally labile analytes like alkaloids, degradation effects also occurred. Increasing the temperatures certainly achieved higher extraction yields but also led to degradation of these thermally labile compounds indicating a necessity for optimization.
\end{abstract}

Keywords: Subcritical Water Extraction; Extraction Yields; Degradation; Hydrastine; Berberine

\section{Introduction}

Goldenseal (Hydrastis canadensis) is a perennial herb native to southeastern Canada and northeastern United States of America [1]. It is amongst the oldest herbal medicinal plants most commonly employed in the Traditional Chinese Medicines [2], and has recently been reported to be one of the five bestselling herbal supplements among dietary supplements sold in the United States of America [3]. The biological activities of goldenseal are associated with the isoquinoline alkaloids hydrastine and berberine (Figure 1) even though the plant also contains other alkaloids including hydrastinine, tetrahydroberberine and canadine [4]. Goldenseal has been used for the treatment of infections, inflammation, as an antibiotic and immune system booster, and it is of current interest as a natural medicine [5]. Therapeutic effects include preventative against cancer and chronic condi- tions [6]. As a result, these factors have increased the interest in using goldenseal as an alternative medicine and herbal supplement [7].

Since the popularity of herbal supplements is rapidly increasing, there is a need for validated analytical methods to determine concentrations of active components present in herbal supplements [7]. One of the major challenges associated with the extraction of compounds present in herbal plants is that most of the target analytes are relatively polar as well as thermally labile [8]. Hydrastine and berberine are particularly sensitive to light and heat [9]. Conventional extraction methods such as reflux, soxhlet and ultrasonic extractions of these compounds are usually performed [10]. These extraction methods employ large volumes of organic solvents at low temperatures over a long period (up to $48 \mathrm{~h}$ ) [11].

The necessity to reduce both the use of organic solvents and the time needed for extracting different 
<smiles>COc1ccc2c(c1OC)C(=O)OC2C1c2cc3c(cc2CCN1C)OCO3</smiles>

(a)<smiles>COc1ccc2cc3[n+](cc2c1OC)CCc1cc2c(cc1-3)OCO2</smiles>

(b)

Figure 1. Chemical Structures of (a) hydrastine and (b) berberine.

analytes from medicinal plants and other environmental matrices has led to newer extraction methods [12]. The use of pressurized liquid extraction (PLE) is an attractive alternative as it achieves fast extractions that are associated with small volume solvent consumption, and exhibit good potential to automate the extraction procedures [13]. PLE has been reported for the extraction of hydrastine and berberine employing organic solvents [14] that are derived from fossil fuel and have relatively high environmental impact. Another method for the extraction of berberine in medicinal plants using supercritical carbon dioxide with organic solvents and surfactants as modifiers was reported [15]. Whereas environmentally friendly carbon dioxide was used at a relatively low temperature $\left(60^{\circ} \mathrm{C}\right)$, the extraction time was rather long $(3 \mathrm{~h})$. Further, organic modifiers were required to improve the yields. Ong et al. have reported a PHWE method for the extraction of berberine in medicinal plants. However, they used ethanol as a modifier and their extraction efficiency was lower $(90 \%)$ [8]. PHWE is a form of PLE in which the solvent used is mainly water. Teo et al. has written a detailed review on the PHWE technique [16].

In the past few years PHWE has received increasing attention as an alternative extraction method. It has been demonstrated that raising the temperature of water above the atmospheric boiling point, with enough pressure to maintain the liquid state allows it to quantitatively extract a variety of organic solutes from different matrices, including analytes present in plant materials [17]. Under such conditions, the fast movement of the water molecules disorders the intermolecular hydrogen bonding, and the dielectric constant (specific permittivity) is lowered, which gives water more non-polar solvent characteristics [18]. Moreover, the viscosity and surface tension of the solvent decrease as the solubility and diffusion rate of the target compounds increase. The penetration of the solvent into the matrix and the transfer of the compounds out from the matrix are faster than in a similar extraction process performed at room temperature $[16,17]$. Hence, compared to conventional extraction methods, the PHWE technique attains more rapid and efficient extractions with minimal consumption of organic solvent [16]. To the best of our knowledge, the application of PHWE in the extraction of alkaloids in medicinal plants and herbal supplements is an area that still remains to be explored.

However, there is a potential challenge in using PHWE for extraction of alkaloids. In theory, high temperatures could be recommended for shorter extractions times and higher extraction yields but in practice degradation of thermally labile compounds may occur if the temperature used is too high [19]. Studies conducted on extraction and degradation of antioxidants from birch bark [20] and anthocyanins from red onion [13] have been conducted. In the current study, both the extraction and degradation of the thermolabile alkaloids present in goldenseal; hydrastine and berberine, using water as the only extraction solvent were investigated.

\section{Experimental}

\subsection{Materials and Methods}

Berberine chloride, hydrastine chloride and hydrastinine chloride standards were purchased from Sigma-Aldrich (Saint Louis, MO, USA). Formic acid and sea sand (acid purified) were purchased from Merck Chemicals (Gauteng, South Africa) while HPLC grade methanol was purchased from Merck KGaA (Darmstadt, Germany). Potassium hydroxide was from Saarchem Analytic (Krugersdorp, South Africa). Goldenseal roots, Willow Products, (Port Elizabeth, South Africa) and capsules, Solgar Corporation, (Leonia, NJ, USA) were purchased from a local herbal store in Grahamstown, South Africa.

\subsection{Instrumentation}

Extraction and degradation experiments were performed in custom-built PHWE equipment featuring a gas chromatographic oven with a maximum temperature of $350^{\circ} \mathrm{C}$. Inside the oven, a pre-heater stainless steel coil was present to maintain the programmed temperature, followed by the extraction cell ( $3 \mathrm{~cm}$ in length and $10 \mathrm{~mm}$ i.d.) closed with screw caps at both ends, which permitted a continuous flow of water. The screw caps contained stainless steel frits, to ensure that the sample remained inside the extraction cell. A cooler system (made from coiled stainless steel tubing) was used to cool the water from the oven temperature to about $25^{\circ} \mathrm{C}$. A restrictor 
controlled the pressure in the system in order to maintain the extracting water in liquid state. The sample was collected in a glass vial. Ultrapure water was pumped using a Bio LC pump Dionex Model GS50 Gradient Pump, Dionex Corporation (Sunnyvale, CA, USA). An ultrasonic extractor from Integral Systems (Randburg, South Africa) was used for the extraction of alkaloids to compare with PHWE while the conventional reflux apparatus were used.

\subsection{HPLC System and Conditions}

For all experiments, Agilent 1200 series (Santa Clara, CA, USA) equipped with a binary pump, an autosampler, column oven and diode array detector (DAD) were used. Separation was achieved on an Agilent ZORBAXE clipse Plus $\mathrm{C}_{18}$ column $(4.6 \mathrm{~mm} \times 75 \mathrm{~mm} \times 3.5 \mu \mathrm{m})$ and detection at $242 \mathrm{~nm}$. The mobile phases used consisted of (A) $0.1 \%$ formic acid (pH 2.7) and (B) methanol, with an isocratic program of $(\mathrm{A} / \mathrm{B}, 40: 60, \mathrm{v} / \mathrm{v})$ and a 6 min run time. The column temperature was set at $35^{\circ} \mathrm{C}$ with a flow rate of $1 \mathrm{~mL} \cdot \mathrm{min}^{-1}$ and injection volume of $5 \mu \mathrm{L}$.

A Finnigan MAT LCQ ion trap mass spectrometer (MS) equipped with an electro spray ionization (ESI) source was used for mass analysis of the degradation products. Spectra were acquired in the positive ion mode, with the capillary temperature set at $200^{\circ} \mathrm{C}$ and sheath gasset at 80 arbitrary units, with the capillary and tube lens voltages set at -20 and $-5 \mathrm{~V}$ respectively.

Water was purified using the Milli-Q system (Billerica, MA, USA) and a Jenway $3510 \mathrm{pH}$ meter manufactured by Bibby Scientific Ltd (Essex, UK) was used to measure the $\mathrm{pH}$.

\subsection{Extraction Procedures}

\subsubsection{Ultrasonication Extraction}

Goldenseal roots were ground and homogenized, and then extracted using a method modified from Hartonen and others [21]. $5 \mathrm{~g}$ was mixed with $50 \mathrm{~mL}$ methanol and then sonicated for $4 \mathrm{~h}$ at $80^{\circ} \mathrm{C}$. The extracts were then filtered using a hydrophobic PVDF $0.45 \mu \mathrm{m}$ Millipore Millex-HV membrane filter (Billerica, MA, USA). The methanolic extracts were diluted 1:3 with water, the $\mathrm{pH}$ adjusted to 7 with $0.1 \mathrm{M}$ potassium hydroxide and then analysed by HPLC-DAD. The experiment was performed in triplicates. The procedure was repeated for goldenseal capsules.

\subsubsection{Reflux Extraction}

$5 \mathrm{~g}$ of the root samples were ground and homogenized and then mixed with $200 \mathrm{~mL}$ methanol, refluxed for $6 \mathrm{~h}$ with continuous stirring then cooled to room temperature, following a method modified from Hartonen and others [21]. The extracts were then filtered using a hydrophobic
PVDF $0.45 \mu \mathrm{m}$ Millipore Millex-HV membrane filter (Billerica, MA, USA). The methanolic extracts were diluted $1: 3(\mathrm{v} / \mathrm{v})$ with water, the $\mathrm{pH}$ adjusted to 7 with $0.1 \mathrm{M}$ potassium hydroxide and then analysis was conducted by HPLC-DAD. The experiment was performed in triplicates and the same procedure was repeated for goldenseal capsules.

\subsubsection{PHWE}

\subsubsection{Extraction Experiment}

$2 \mathrm{~g}$ of goldenseal roots which were previously ground and homogenized were mixed with $2 \mathrm{~g}$ of sea sand, to avoid conglomeration and any void space in the extraction cell. To optimize the temperature, pressure, flow rate and time required for extraction, the temperatures were varied from $100^{\circ} \mathrm{C}$ to $160^{\circ} \mathrm{C}$, pressures from 10 to 100 bars, flow rate from 0.5 to $1.5 \mathrm{~mL} \cdot \mathrm{min}^{-1}$ and extraction time was varied from 5 to $60 \mathrm{~min}$ using water as the only solvent. The samples were collected in a glass vial at 3 min intervals. The eluate was mixed with methanol $(3: 1$ $\mathrm{v} / \mathrm{v}$ ) the $\mathrm{pH}$ adjusted to 7 with $0.1 \mathrm{M}$ potassium hydroxide and analyzed by HPLC-DAD. The experiment was performed in triplicates and the procedure was repeated for goldenseal capsules.

\subsubsection{Degradation Experiment}

Thermal degradation of hydrastine was carried out using both a standard and a sample. $3 \mathrm{~mL}$ of a $100 \mu \mathrm{g} \cdot \mathrm{mL}^{-1}$ (n $=3$ ) freshly prepared hydrastine standard was put in an autoclave (Rodwell Scientific Instruments, Basildon, UK) and then heated to $160^{\circ} \mathrm{C}$ for $30 \mathrm{~min}$, with a pre-heating time of $10 \mathrm{~min}$, prior to HPLC-DAD analysis. A sample was taken out for analysis at time zero before heating the autoclave. For goldenseal samples, the extracts collected in section 2.4.3.1 (Extraction) were subjected to the same conditions.

\subsection{Validation Parameters}

A stock solution containing $1000 \mu \mathrm{g} \cdot \mathrm{mL}^{-1}$ alkaloids was diluted to obtain standard solutions in the concentration range of $0-120 \mu \mathrm{g} \cdot \mathrm{mL}^{-1}$ to establish the linearity range. Analysis was carried out in triplicate by injecting $5 \mu \mathrm{L}$ of each solution. Peak areas were plotted against the corresponding concentrations to obtain a calibration graph. Intra and inter-day precisions were established by analyzing 20,60 and $100 \mu \mathrm{g} \cdot \mathrm{mL}^{-1}$ of the alkaloids solution, three times on the same day and on three consecutive days, respectively. Accuracy was determined by analyzing a known concentration of the alkaloids, viz., 20, 60 and $100 \mu \mathrm{g} \cdot \mathrm{mL}^{-1}$ spiked with sample in triplicate followed by the determination of the percent recovery. The signal to noise ratio was evaluated at 3:1 and 10:1 for limit of detection (LOD) and limit of quantification (LOQ), respectively. 


\section{Results and Discussion}

\subsection{Optimization of Extraction Procedures}

\subsubsection{Effects of Temperature in PHWE}

The peak areas of hydrastine and berberine were used as evaluation criteria for the optimization of temperature, time and pressure. Of all the parameters evaluated in this study, generally, it was observed that temperature had the greatest effect while pressure had negligible effect on the extraction efficiency. Data obtained for both hydrastine and berberine $(\mathrm{n}=3)$ indicated that the highest extraction yield was obtained within $15 \mathrm{~min}$ and it increased with increasing temperature only up to $140^{\circ} \mathrm{C}$. Above $140^{\circ} \mathrm{C}$, extraction yields decreased (see Figure 2). This was attributed to possible degradation since the analytes are thermally labile.

\subsubsection{Comparison of PHWE with Conversional Methods}

Both PHWE and the selected conventional methods have demonstrated to be efficient in the extraction of hydrastine and berberine (Table 1). At a temperature of $140^{\circ} \mathrm{C}$, pressure of 50 bars and a flow rate of $1 \mathrm{~mL} \cdot \mathrm{min}^{-1}$ with 15 min extraction time, the total extraction yields of both the alkaloids in the root sample was $43.04 \mathrm{mg} \cdot \mathrm{g}^{-1}(\mathrm{n}=3)$. These were comparable to those of reflux and ultrasonic extractions (39.07 and $45.67 \mathrm{mg} \cdot \mathrm{g}^{-1}$ respectively). At $95 \%$ confidence level $(\mathrm{n}=3)$ using the student $t$ test, recorded reflux and ultrasonic extraction yields were not significantly different from those of PHWE. PHWE employed only water as the extraction medium to achieve comparable yields to those of conventional methods. Moreover, the extraction time was shorter (15 $\mathrm{min})$ compared to over $6 \mathrm{~h}$ for the conventional methods.

\subsection{Degradation Behavior}

The optimized HPLC method was used to further study the degradation behavior of hydrastine under various high temperatures conditions using PHWE. The corresponding chromatograms are shown in Figure 3. Only hydrastine was further investigated due to lack of berberine standard. Hydrastine showed only one major peak (4 min) at the optimal temperature of $140^{\circ} \mathrm{C}$ (Figure 3(a)). However, at elevated temperatures, $160^{\circ} \mathrm{C}$ and $180^{\circ} \mathrm{C}$, some extra peaks in the lower time zone were observed. The extra peaks were assumed to be degradation prod-

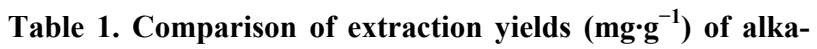
loids in goldenseal by PHWE, reflux and sonication.

\begin{tabular}{cccc}
\hline & PHWE & Reflux & Sonication \\
\hline $\begin{array}{c}\text { Alkaloids in } \\
\text { goldenseal roots } \\
\begin{array}{c}\text { Alkaloids in } \\
\text { goldenseal capsules }\end{array}\end{array}$ & $43.04(2.84)$ & $39.07(1.68)$ & $45.67(2.97)$ \\
\hline & & $36.65(2.04)$ & $39.23(1.78)$ \\
\hline
\end{tabular}

$\operatorname{RSD}(n=3)$.

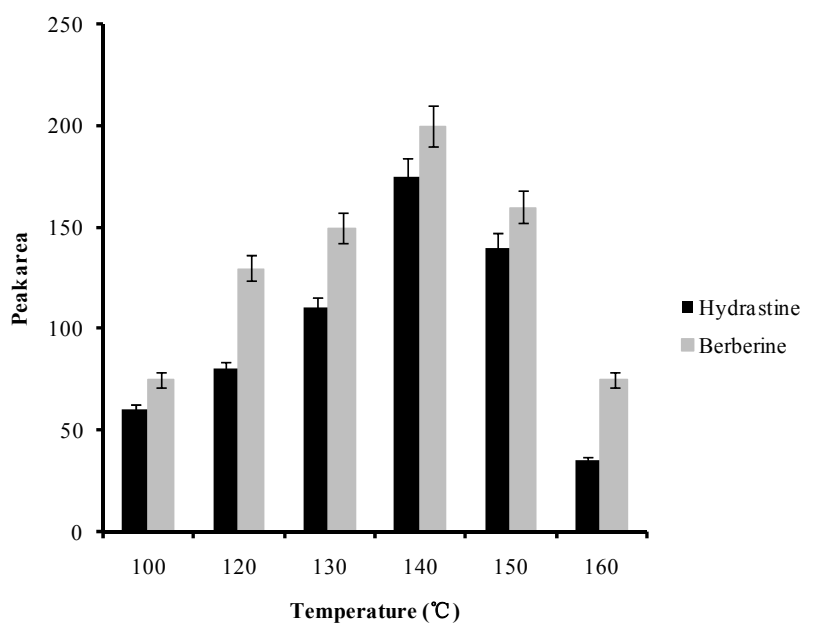

Figure 2. Effects of temperature on the extraction of hydrastine and berberine from goldenseal roots by PHWE at 50 bars, $1 \mathrm{~mL} \cdot \mathrm{min}^{-1}$ for $15 \mathrm{~min}$.

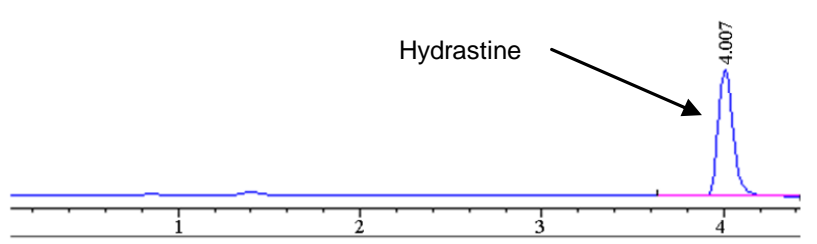

(a)

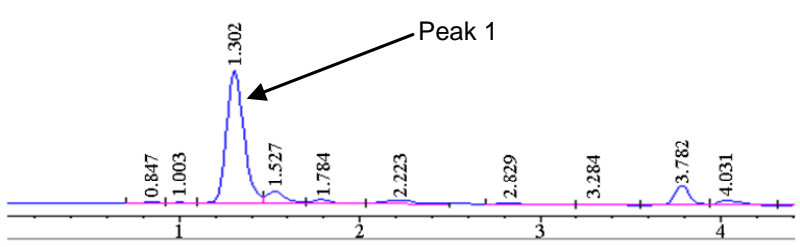

(b)

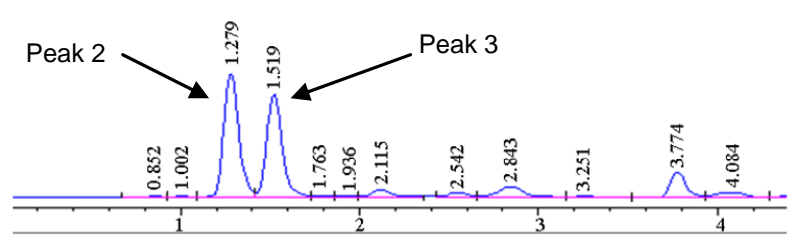

(c)

Figure 3. Chromatograms showing degradation products (Peak 1, 2 and 3 ) of hydrastine standard $\left(100 \mu \mathrm{g} \cdot \mathrm{mL}^{-1}\right)$ at (a) $140^{\circ} \mathrm{C}$, (b) $160^{\circ} \mathrm{C}$ and (c) $180^{\circ} \mathrm{C} 50$ bars, $30 \mathrm{~min}$.

ucts rather than new analytes (Figures 3(b) and (c)). It was also noted that the number of extra peaks increased as the temperature was increased. The disappearance of the hydrastine peak was attributed to it changing into its degradation products.

\subsection{Extraction/Degradation Curves}

Figure 4(a) represents the extraction profile of hydrastine while Figure 4(b) and (c) represents the degradation 
of hydrastine for sample and standard respectively. Degradation starts immediately at the beginning of the experiment even during the $10 \mathrm{~min}$ pre-heating stage. Within the first $10 \mathrm{~min}$ of the experiment, $25 \%$ of the original sample had already degraded while $41 \%$ of the standard had degraded. Also, the rate of degradation for a standard is faster than that of the sample. The difference in the degradation pattern was attributed to the matrix presence which seems to have a "protective effect" on the sample. The root matrix may possibly have some other alkaloids or other antioxidants that slow down the degradation of hydrastine. Petersson et al. have demonstrated the role of the matrix in the degradation experiments of anthocyanins in red cabbage [13].

\subsection{Kinetics of Hydrastine Thermal Degradation}

Figure 5 shows the relationship between the concentration of the hydrastine standard and time over a temperature range of $100^{\circ} \mathrm{C}-160^{\circ} \mathrm{C}$. As expected, it was observed that the concentration decreased with time and that alkaloids were more rapidly degraded at higher temperatures. A plot of the logarithm of concentration

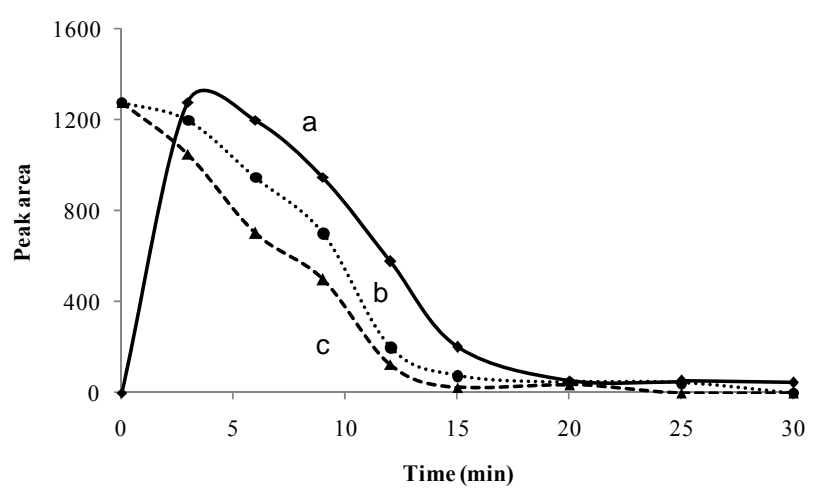

Figure 4. Extraction curve at $140^{\circ} \mathrm{C}$ (a), and degradation curves for sample (b) and a standard (c) of hydrastine at $160^{\circ} \mathrm{C}$ at $50 \mathrm{bars}, 1 \mathrm{~mL} \cdot \mathrm{mL}^{-1}$ for $15 \mathrm{~min}$.

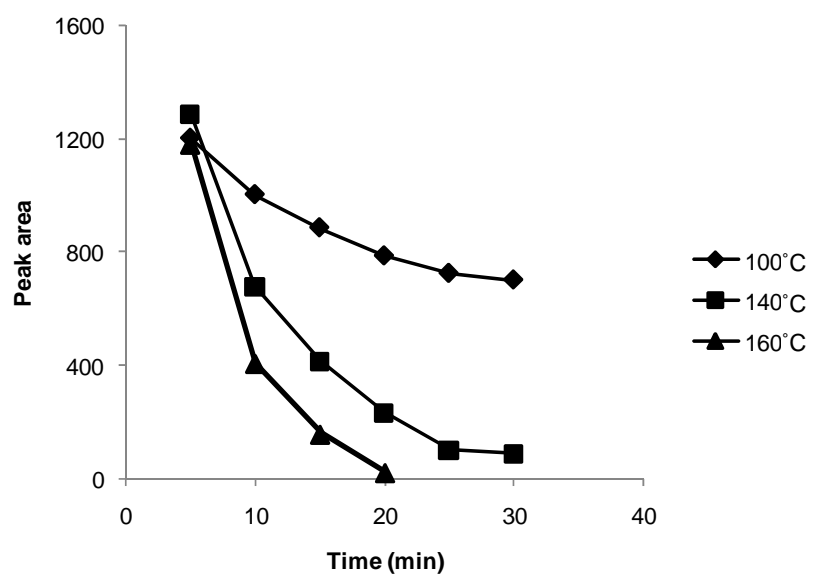

Figure 5. Relation of concentration of hydrastine and time at $100^{\circ} \mathrm{C}, 140^{\circ} \mathrm{C}$ and $160^{\circ} \mathrm{C}$ bars, $1 \mathrm{~mL} \cdot \mathrm{min}^{-1}$ for $15 \mathrm{~min}$. against time resulted in pseudo first-order reaction kinetics (results not shown).

\subsection{Peak Identification}

The degradation products were tentatively identified mass spectrometry (MS). The MS data was compared to molar masses of the fragmentation pattern based on literature. Only one match corresponding to hydrastinine was found at m/z value of 208 (see peak 1 in Figure 3) [22]. However, the rest of the degradation products were not positively identified.

\subsection{Analytical Parameters}

The method was found to be linear in the concentration range of $0-120 \mu \mathrm{g} \cdot \mathrm{mL}^{-1}\left(\mathrm{r}^{2}=0.9992\right)$ for both the alkaloids. The data for triplicate analysis showed that the $\%$ R.S.D. for each investigated concentration was $<0.25 \%$. The \% R.S.D. for intra- and inter-day precision at three different concentrations, viz., 20, 60, and $100 \mu \mathrm{g} \cdot \mathrm{mL}^{-1}$ was $<0.40 \%$. Also, good recoveries were obtained (over $95 \%$ ) when samples were spiked with known concentration of the drug at 20,60 , and $100 \mu \mathrm{g} \cdot \mathrm{mL}^{-1}$. The limits of detection (LOD) and quantification (LOQ) were found to be 0.50 and $1.65 \mu \mathrm{g} \cdot \mathrm{mL}^{-1}$ respectively for hydrastine and 0.47 and $1.55 \mu \mathrm{g} \cdot \mathrm{mL}^{-1}$ respectively for berberine.

\section{Conclusion}

A method for the extraction of medium polar and thermally labile hydrastine and berberine from goldenseal has successfully been developed. The proposed method utilized only water as extraction solvent and it achieved extraction yields comparable to those of conventional methods. However, at certain temperature degradation takes over extraction and therefore optimization is very important. The method could potentially be applied to other medicinal plants and herbal supplements which are now not only becoming popular but also taking into consideration the temperatures used.

\section{Acknowledgements}

This work was supported by Agilent Technologies (USA), United Nations Development Program-Global Environmental Facility-Small Grants Programme Botswana (UNDP-GEF/SGF-Botswana), Andrew Mellon Foundation and STINT (the Swedish Foundation for International Cooperation in Research and Higher Education, YR2009-7015).

\section{REFERENCES}

[1] A. T. Borchers, C. L. Keen, J. S. Stern and E. M. Gershwin, "Inflammation and Native American Medicine: The Role of Botanicals," The American Journal of Clini- 
cal Nutrition, Vol. 72, No. 2, 2000, pp. 339-347.

[2] N. P. Brown and M. C. Roman, "Determination of Hydrastine and Berberine in Goldenseal Raw Materials, Extractsand Dietary Supplements by High-Performance Liquid Chromatography with UV: Collaborative Study," Journal of AOAC International, Vol. 91, No. 4, 2008, pp. 694-701.

[3] M. Govindan and G. Govindan, "A Convenient Method for the Determination of Quality of Goldenseal," Fitoterapia, Vol. 71, No. 3, 2000, pp. 232-235. doi:10.1016/S0367-326X(99)00162-8

[4] American Herbal Pharmacopoeia and Therapeutic Compendium, "Goldenseal Root (Hydrastis canadensis): Standard of Analysis, Quality Control and Therapeutics," Santa Cruz, 2001, pp. 10-18.

[5] H. A. Weber, M. K. Zart, S. L. Ferguson, J. G. Greaves, A. P. Clark, R. K. Harris and D. J. C. S. Smith, "Separation and Quantitation of Isoquinoline Alkaloids Occurring in Goldenseal," Journal of Liquid Chromatography \& Related Technologies, Vol. 24, No. 1, 2001, pp. 87-95. doi:10.1081/JLC-100000329

[6] L.-Q. Tang, W. Wei, I.-M. Chen and S. Liu, "Effects of Berberine on Diabetes Induced by Alloxan and a HighFat/High-Cholesterol Diet in Rats," Journal of Ethnopharmacology, Vol. 108, No. 1, 2006, pp. 109-115. doi:10.1016/j.jep.2006.04.019

[7] P. K. Gupta, M. Hubbard, B. Gurley and H. P. Hendrickson, "Validation of a Liquid Chromatography-Tandem Mass Spectrometric Assay for the Quantitative Determination of Hydrastine and Berberine in Human Serum," Journal of Pharmaceutical and Biomedical Analysis, Vol. 49, No. 4, 2009, pp. 1021-1026. doi:10.1016/j.jpba.2009.01.036

[8] E. S. Ong and S. M. Len, "Pressurized Hot Water Extraction of Berberine, Baicalein and Glycyrrhizin in Medicinal Plants," Analytica Chimica Acta, Vol. 482, No. 1, 2003, pp. 81-89. doi:10.1016/S0003-2670(03)00196-X

[9] A. Sinclair and P. M Catling, "Ontario Goldenseal, Hydrastis canadensis, Populations in Relation to Habitat Size, Paths, and Woodland Edges," Canadian FieldNaturalist, Vol. 114, No. 4, 2000, pp. 652-655.

[10] F. Li, S. Sun, J. Wang and D. Wang, "Chromatography of Medicinal Plants and Chinese Traditional Medicines," Biomedical Chromatography, Vol. 12, No.2, 1998, pp. 78-85.

doi:10.1002/(SICI)1099-0801(199803/04)12:2<78::AIDBMC726>3.0.CO;2-U

[11] H. J. Issaq, "Capillary Electrophoresis of Natural Products-II," Electrophoresis, Vol. 20, No. 15-16, 1999, pp. 3190-3202.

doi:10.1002/(SICI)1522-2683(19991001)20:15/16<3190:: AID-ELPS3190>3.0.CO;2-K

[12] S. B. Hawthorne, S. Trembley, C. L. Moniot, C. B. Grabanski and D. J. Miller, "Static Subcritical Water Extrac- tion with Simultaneous Solid-Phaseextraction for Determining Polycyclic Aromatichydrocarbons on Environmental Solids," Journal of Chromatography A, Vol. 886, No. 1-2, 2000, pp. 237-244.

[13] E. V. Petersson, J. Liu, P. J. R. Sjöberg, R. Danielsson and C. Turner, "Pressurized Hot Water Extraction of Anthocyanins from Red Onion: A Study Onextraction and Degradation Rates," Analytica Chimica Acta, Vol. 663, No. 1, 2010, pp. 27-32. doi:10.1016/j.aca.2010.01.023

[14] G. W. Schieffer and K. Pfeiffer, "Pressurized Liquid Extraction and Multiple, Ultrasonically-Assisted Extractions of Hydrastine and Berberine from Goldenseal (Hydrastis canadensis) with Subsequent HPLC Assay," Journal of Liquid Chromatography \& Related Technologies, Vol. 24, No. 16, 2001, pp. 2415-2427.

[15] B. Liu, W. Li, Y. Chang, W. Dong and L. Ni, "Extraction of Berberine from Rhizome of Coptis chinensis Franch Using Supercritical Fluid Extraction," Journal of Pharmaceutical and Biomedical Analysis, Vol. 41, No. 3, 2006, pp. 1056-1060. doi:10.1016/j.jpba.2006.01.034

[16] C. C. Teo, S. N. Tan, J. W. H. Yong, C. S. Hew and E. S. Ong, "Pressurized Hot Water Extraction," Journal of Chromatography A, Vol. 1217, No. 16, 2010, pp. 24842494. doi:10.1016/j.chroma.2009.12.050

[17] C. L. Hsieh, J. J. Lin, S. Y. Chiang, S. Y. Su, N. Y. Tang, G. G. Lin, I. H. Lin, C .H. Liu, C. Y. Hsiang, J. C. Chen and T. Y. Ho, "Gastrodiaelata Modulated Activator Protein 1 via c-Jun N-Terminal Kinase Signaling Pathway in Kainic Acid-Induced Epilepsy in Rats," Journal of Ethnopharmacology, Vol. 109, No. 2, 2007, pp. 241-247. doi:10.1016/j.jep.2006.07.024

[18] J. Kronholm, K. Hartonen and M. L. Riekkola, "Analytical Extractions with Water Atelevated Temperatures and Pressures," Trends in Analytical Chemistry, Vol. 26, No. 5, 2007, pp. 396-412.

[19] T. Andersson, K. Hartonen, T. HyÖtyläinen and M.-L. Riekkola, "Stability of Polycyclic Aromatic Hydrocarbons in Pressurised Hot Water," Analyst, Vol. 128, No. 2, 2003, pp. 150-155. doi:10.1039/b211447j

[20] M. Co, C. Zettersten, L. Nyholm P. R. Sjöberg and C. Turner, "Degradation Effects in the Extraction of Antioxidants from Birch Bark Using Water at Elevated Temperature and Pressure," Analytica Chimica Acta, Vol. 716, 2011, pp. 40-48. doi:10.1016/j.aca.2011.04.038

[21] K. Hartonen, J. Parshintsev, K. Sandberg, E. Bergelin, L. Nisula and M.-L. Riekkola, "Isolation of Flavonoids from Aspen Knotwood by Pressurized Hot Water Extraction and Comparison with Other Extraction Techniques," Talanta, Vol. 74, No. 1, 2007, pp. 32-38.

doi:10.1016/j.talanta.2007.05.040

[22] R. N. Gupta and I. D. Spencer, "Biosynthetic Incorporation of One-Carbon Units into Berberine and Hydrastine," Canadian Journal of Chemistry, Vol. 43, No. 1, 1965, pp. 133-144. doi:10.1139/v65-016 